\title{
MAJOR MATERIALS FACILITIES
}

\author{
The Annual Meeting Plenary Session Will Highlight \\ The Report Of The NAS's Major Materials Facilities Committee
}

In keeping with our tradition of bringing the most significant current issues in materials development under the scrutiny of our members at the Annual Meeting Plenary Session, the Materials Research Society is pleased to announce that this year's Session will be devoted to the work of the National Academy of Sciences' Major Materials Facilities Committee. MRS members learned personally of this important undertaking at last year's Plenary Session from the scientist who requested that the matter be taken up, President Reagan's Science Advisor, Dr. George Keyworth. MRS Vice President Bill R. Appleton, Chairman of the 1984 Plenary Session, provides this report:

\section{Priorities for Materials Research}

"At the Plenary Session of last year's Annual Meeting of the Society, we heard from George Keyworth, Presidential Science Advisor and Director of the Office of Science and Technology Policy (OSTP), that the materials science community needed to establish priorities in order most effectively to allocate resources to the most significant areas of materials research. As Dr. Keyworth stressed, this challenge is particularly complex because of the diverse and multifaceted nature of materials research and development.

"In November 1983 the OSTP asked the National Research Council of the National Academy of Sciences to assist in establishing priorities for major facilities for materials research. The facilities are defined as those with initial costs of at least $\$ 5$ million and include, among others, sources of synchrotron radiation and steady-state and pulsed neutrons.

“A Major Materials Facilities Committee of 22 members was formed within the NRC Commission on Physical Sciences, Mathematics, and Resources, to address this charge. The membership of the committee, which is cochaired by F. Seitz and D.E. Eastman, represents the diverse disciplines that use major facilities for materials research. It also reflects the differing research approaches and the broad spectrum of organizations where such research is done.

\section{Conclusions and Recommendations}

"The Plenary Session of the 1984 MRS Annual Meeting will present the conclusions and recommendations of the Major Materials Facilities Committee to the MRS membership. We are very fortunate to have as our keynote speaker Dr. Dean E. Eastman, co-chairman of this committee. He brings to this task a broad perspective. He has served on numerous distinguished scientific committees, and is presently Director of the Advanced Packaging Technology Laboratory of International Business Machines Corporation. Dr. Eastman also has been a highly successful user of an existing major facility during his career."

Dr. Eastman will address the entire MRS membership in a program that begins at 6 p.m. Monday, Nov. 26, following the first full day of technical symposia at the Annual Meeting. Bill Appleton notes: "Our Plenary Sessions always provide ample time for members from the floor to ask questions of our speakers. These interchanges are always lively and often provocative. Given the special significance of this year's topic, we look forward to a particularly stimulating exchange of information and views."

\section{CHAIRMEN FOR '85}

\section{[Continued from Page 7]}

invited papers in the symposia on laser annealing, defects in semiconductors, and resonance spectroscopies. $\mathrm{He}$ is currently a member of the Society's Program Committee.

\section{John Fan}

John C.C. Fan received his B.S. degree in 1966 from the Department of Electrical Engineering of the University of California at Berkeley, and his M.S. and Ph.D. degrees in Applied Physics from Harvard University in 1972. Since then he has worked with Lincoln Laboratory, where he is Associate Leader of the Electronic Materials Group. He is the author or co-author of about 150 publications in the fields of thin films and crystals of semiconductors, solar cells, and solid state electronic and optical materials and devices. Currently, John is a Councillor of the MRS, a member of the Corporate Participation Committee, and a member of the editorial board of the MRS-affiliated letters journal, Materials Letters. He was co-chairman of the symposium on energy beam-solid interactions and transient thermal processing at the 1983 Annual Meeting, and has given invited talks and chaired sessions at many MRS symposia. John also is a member of the editorial boards of Solar Cells and Applied Physics Communications, and is a member-at-large of the Executive Committee of the Electronics Division of The Electrochemical Society. 